\title{
Retraction
}

\section{Retraction: Improvement of Landfill Leachate Biodegradability with Ultrasonic Process}

\section{The PLOS ONE Editors}

It has been brought to the attention of the PLOS ONE editors that this article contains substantial overlap in text and scientific content with the two publications below by the same authors:

E-Journal of Chemistry, Volume 9 (2012), Issue 2, Pages 766771

http://dx.doi.org/10.1155/2012/820971

Improvement of Landfill Leachate Biodegradability with Ultrasonic Process

Braz J Chem Eng Vol.29 no.2

http://dx.doi.org/10.1590/S0104-66322012000200003

Use of a sonocatalytic process to improve the biodegradability of landfill leachate

The PLOS ONE editors retract this article as we consider that this constitutes redundant publication.

The second author Ali Akbar Roodbari has taken responsibility for the duplication, the other authors were unaware of the different submissions for the manuscript

\section{Reference}

1. Mahvi AH, Roodbari AA, Nabizadeh Nodehi R, Nasseri S, Dehghani MH, et al. (2012) Improvement of Landfill Leachate Biodegradability with Ultrasonic Process. PLoS ONE 7(7): e27571. doi:10.1371/journal.pone.0027571
Citation: The PLOS ONE Editors (2014) Retraction: Improvement of Landfill Leachate Biodegradability with Ultrasonic Process. PLoS ONE 9(4): e96133. doi:10.1371/journal.pone.0096133

Published April 18, 2014

Copyright: (c) 2014 The PLOS ONE Editors. This is an open-access article distributed under the terms of the Creative Commons Attribution License, which permits unrestricted use, distribution, and reproduction in any medium, provided the original author and source are credited. 